\title{
Medically Important Parasites Carried by Cockroaches in Melong Subdivision, Littoral, Cameroon
}

\author{
R. J. Atiokeng Tatang, H. G. Tsila, and J. Wabo Poné \\ Research Unit of Biology and Applied Ecology, Department of Animal Biology, Faculty of Science, University of Dschang, \\ P.O. Box 067, Dschang, Cameroon
}

Correspondence should be addressed to J. Wabo Poné; waboponejosue@yahoo.fr

Received 24 April 2017; Revised 20 June 2017; Accepted 17 July 2017; Published 20 August 2017

Academic Editor: José F. Silveira

Copyright (C) 2017 R. J. Atiokeng Tatang et al. This is an open access article distributed under the Creative Commons Attribution License, which permits unrestricted use, distribution, and reproduction in any medium, provided the original work is properly cited.

Cockroaches have been recognized as mechanical vectors of pathogens that can infest humans or animals. A total of 844 adult cockroaches (436 males and 408 females) were caught. In the laboratory, cockroaches were first washed in saturated salt solution to remove ectoparasites and then rinsed with $70 \%$ alcohol, dried, and dissected for endoparasites. An overall transport rate of 47.39\% was recorded. Six genera of parasites were identified. These were Ascaris (33.76\%), Trichuris (11.97\%), Capillaria (6.16\%), Toxocara (4.86\%), Hook Worm (4.86\%), and Eimeria (2.73\%). The parasites were more recorded on the external surface (54.27\%) of cockroaches than in the internal surface (GIT, 38.51\%). The same tendency was obtained between sexes with female cockroaches having a higher transport rate (36.69\%). Cockroaches caught in toilets carried more parasites (31.99\%) as compared to those from kitchens (22.63\%) and houses (11.14\%). Almost all encountered parasites were recognized as responsible of zoonosis and they can be consequently released in nature by hosts and easily disseminated by cockroaches as mechanical vectors. Sanitary education, reenforcement of worms' eradication programs, and the fight against these insects remain a necessity in the Mélong Subdivision.

\section{Introduction}

Cockroaches have survived on the earth for more than 300 million years virtually without involving change [1]. They are considered one of the most successful groups of animals because of their adaptability in various environmental conditions. There are approximately 3500 species of cockroaches worldwide [2]. Among these species, thirty are associated with human habitations [3]. Periplaneta americana, Linnaeus, 1758, and Blattella germanica, Linnaeus, 1767 , are the most common species $[4,5]$. The majority of these species lives in tropical and subtropical areas where they are not recognized as pests [6]. In these areas, they are abundantly found in areas with frequent stagnant water bodies or with a constant and high moisture availability such as toilets, kitchens, sewages, and drainages where water serves as migration routes from place to place [7]. In addition to their repulsive and annoying characteristics, they eat and contaminate food and leave a persistent offensive odor in infested places [1]. Cockroaches frequently feed on human faeces, garbage, and sewage [8]. Therefore they have copious opportunities to disseminate pathogenic agents on food resources. They are nocturnal and have filthy habits which coupled with their feeding mechanisms make them efficient vectors of pathogens like bacteria (Klebsiella pneumonia, Enterobacter cloacae, Enterobacter aerogenes, Salmonella spp., Shigella sonnei, Vibrio cholerae, Citrobacter freundii [9], viruses (Poliomyelitis)) [10], protozoa (oocysts of Isospora belli, Cryptosporidium parvum, Cyclospora cayetanensis, cysts of Entamoeba histolytica, Balantidium coli, and Giardia lamblia) [8, 11-13], fungi (Candida sp., Rhizopus sp., Aspergillus sp., Mucor sp.) [14], and eggs of some pathogenic intestinal worms (Ascaris lumbricoides, Trichuris trichiura, Hookworm, Enterobius vermicularis, Hymenolepis nana, Toxocara canis, and Strongyloides stercoralis larvae) [15-17]. Cockroaches not only contaminate food with their droppings or by pathogens but they also cause food poisoning [18]. According to Tatfeng et al. [14], some people are allergic to antigens and faeces of cockroaches which may result in asthmatic-related health problems. Studies have been carried out in several countries of the world in order to evaluate the risks of parasitic infestation associated with the presence of cockroaches in 
households. In Cameroon, to the best of our knowledge, no or few epidemiological data on this risk factor associated with the presence of cockroaches in the households are available. The present study was therefore designed to identify cockroach species while examining the occurrence of medically important parasites they carried in the Melong Subdivision, Littoral Region, Cameroon. The findings may be of immense benefit to the local residents and for others within and outside Cameroon as it will serve as an educational tool for the potential dangers they might face with the presence of cockroaches in their houses.

\section{Materials and Methods}

2.1. Study Area. The study was carried out in Melong Subdivision of the Moungo Division, Littoral Region of Cameroon, with the following coordinate at Latitude $5^{\circ} 07^{\prime} 22^{\prime \prime}$ North and Longitude $9^{\circ} 57^{\prime} 08^{\prime \prime}$ East. The locality experiences two rainy seasons: the longer one runs from June 20th to November 15th and a shorter one goes from March 20th to April 15th with an annual average rainfall of $1960 \mathrm{~mm}$ and two dry seasons from November 20th to March 15th for the larger one and April 20th to May 15th for the shorter one. Average temperature ranges from $22.5^{\circ} \mathrm{C}$ to $24^{\circ} \mathrm{C}$. People of Melong Subdivision are predominately peasant farmers. Their sanitary conditions are below standard. Due to the lack of pipe borne water supply, they depend sufficiently on spring and well water for most of their occupational and domestic activities. With no toilet facilities, a majority use man-hole toilets while others defecate on road sides and bushes and refuse dumps. Their system of animal husbandry is underdeveloped. So, they are frequently in contact with animals like pigs, dogs, goats, and cats. These facilities largely contribute to the proliferation of cockroaches which are reported to be serious vectors of pathogens.

2.2. Sample Collection. A total of eight hundred and fortyfour (844) adult cockroaches were caught in three-quarters (Nkongsoung, Melong Centre and Lèlem) of Melong Subdivision in the night from 63 households randomly selected between $8.00 \mathrm{pm}$ and $11.00 \mathrm{pm}$ in toilets, kitchens, and houses using sterile hand gloves. Each cockroach was preserved in labeled sterile vial containing cotton soaked in diluted $10 \%$ chloroform. Containers were transported in an ice back to the laboratory for identification and parasitological analyses.

\subsection{Identification of Cockroaches and Parasitological Analysis.} Once in the laboratory, cockroaches were identified according to their morphological and morphometric characteristics using standard taxonomic keys [19]. For ectoparasites analysis, $32 \mathrm{ml}$ of saturated salt solution (40\%) was added to the vial containing the cockroach. The vial was shaken for $2 \mathrm{~min}$ to remove attached parasites [16]. Then, $16 \mathrm{ml}$ of the suspension was transferred in two test tubes until an upper meniscus was formed. Immediately, cover slides were carefully placed on top of the tubes. The preparation was allowed to stand for $10 \mathrm{~min}$ to allow parasitic stages to float and fix on the slides. Then, cover slides were delicately removed and placed on a slide and the preparation was examined using light microscope at 10x for the identification of parasites [20]. For cysts and oocysts identification, one drop of $1 \%$ Lugol's iodine was added at the border of the cover slides and the preparation was observed at 40x. As far as internal parasites were concerned, washed cockroaches were individually placed in flask and rinsed with $70 \%$ alcohol. They were then transferred into sterilized flake and allowed to dry at room temperature $\left(25^{\circ} \mathrm{C}\right)$ and then washed with normal saline for 2-3 min. After washing, each cockroach was fixed in a Petri dish. The head and legs were isolated and the abdomen was opened using fine pointed forceps with small scissors. The gut and other internal organs were removed using fine needles. The GIT of the cockroach was removed, opened, and washed in a vial with $32 \mathrm{ml}$ of saturated salt solution (40\%). This was homogenized and filtered using a tea sieve. About $20 \mathrm{ml}$ of the filtrate was used to fill a test tube until an upper meniscus was formed. Then the same procedure was followed as described earlier.

2.4. Statistical Analyses. Descriptive statistics were used to determine the transport rate while Chi-squared $\left(\chi^{2}\right)$ analysis was used to determine association and significant differences between the parameters tested at $p<0.05$.

\section{Results}

3.1. Distribution of Cockroaches per Quarters and Capture Sites. A total of 844 adult cockroaches were collected from 63 households randomly selected during the period of survey. Three species of cockroach, Periplaneta americana, Blattella germanica, and Blatta orientalis were identified (Table 1). Almost all the species were found in the three-quarters of the study area.

All the species of cockroach identified were found in all capture sites. Irrespective of the capture sites, the most prevalent species was $P$. americana $(58.41 \%)$, followed by B. germanica $(21.45 \%)$ and B. orientalis $(20.14 \%)$ (Table 1 ). Out of the cockroaches encountered, $P$. americana had the highest prevalence in toilets $(33.80 \%)$, as compared to kitchens (15.62\%) and houses (9.48\%). Blattella germanica was most prevalent in houses (14.10\%) and kitchens (7.35\%). This species was absent in toilets. Blattella orientalis was also most prevalent in houses $(10.19 \%)$ followed by kitchens (9.95\%) and absent in toilets.

3.2. Cockroaches Parasitic Transport Rate. Out of 844 cockroaches caught, 400 (47.39\%) were found to be carriers of nematodes eggs and protozoan oocysts. From these cockroaches, $256(30.33 \%)$ were $P$. americana followed by 76 (9.00\%) B. germanica and $68(8.06 \%)$ B. orientalis.

3.3. Species of Parasites Identified. The different medically important parasites isolated from external and internal surfaces of cockroaches are presented in Figure 1. It is found that the most prevalent medically important parasitic stage identified was Ascaris spp. eggs (33.76\%) followed by that of Trichuris spp. (11.97\%) and Capillaria spp. (6.16\%). Eggs of 


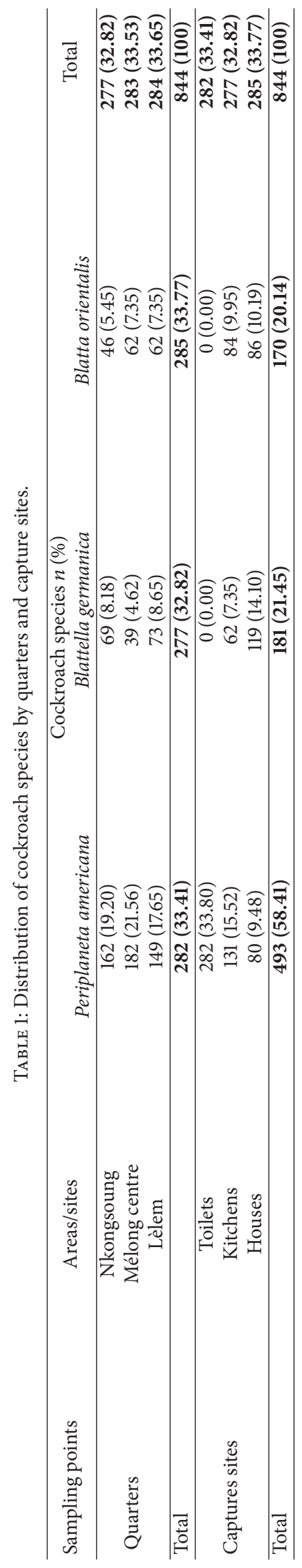


TABLE 2: Prevalence of parasites grouped by sites of infestation and by sexes of cockroaches.

\begin{tabular}{|c|c|c|c|c|c|c|}
\hline \multirow{2}{*}{ Parasite } & \multicolumn{2}{|c|}{ Sites of infestation } & \multirow{2}{*}{ Total } & \multicolumn{2}{|c|}{ Sexes } & \multirow{2}{*}{ Total } \\
\hline & External surface & Internal surface & & Male & Female & \\
\hline Ascaris spp. & $240(28.44)^{\mathrm{a}}$ & $179(21.21)^{\mathrm{b}}$ & $419(49.64)$ & $101(11.97)^{\mathrm{a}}$ & $184(21.80)^{\mathrm{b}}$ & $285(33.76)$ \\
\hline Trichuris spp. & $81(9.60)^{\mathrm{a}}$ & $58(6.87)^{\mathrm{b}}$ & $139(16.46)$ & $47(5.57)^{\mathrm{a}}$ & $54(6.40)^{\mathrm{a}}$ & $101(11.97)$ \\
\hline Capillaria spp. & $46(5.45)^{\mathrm{a}}$ & $31(3.67)^{\mathrm{a}}$ & 77 (9.12) & $28(3.32)^{\mathrm{a}}$ & $24(2.84)^{\mathrm{a}}$ & $52(6.16)$ \\
\hline Toxocara spp. & $38(4.50)^{\mathrm{a}}$ & $28(3.32)^{\mathrm{a}}$ & $66(7.82)$ & $26(3.08)^{\mathrm{a}}$ & $15(1.78)^{\mathrm{a}}$ & $41(4.86)$ \\
\hline Hookworm & $30(3.55)^{\mathrm{a}}$ & $12(1.42)^{\mathrm{b}}$ & $42(4.98)$ & $13(1.54)^{\mathrm{a}}$ & $28(3.32)^{\mathrm{b}}$ & $41(4.86)$ \\
\hline Eimeria spp. & $23(2.73)^{\mathrm{a}}$ & $17(2.01)^{\mathrm{a}}$ & $40(4.74)$ & $12(1.42)^{\mathrm{a}}$ & $11(1.30)^{\mathrm{a}}$ & $23(2.73)$ \\
\hline
\end{tabular}

$\mathrm{a}$ and $\mathrm{b}$ on the same column $=$ significant at $0.05-\mathrm{a}$, a on the same line $=$ nonsignificant at 0.05 .

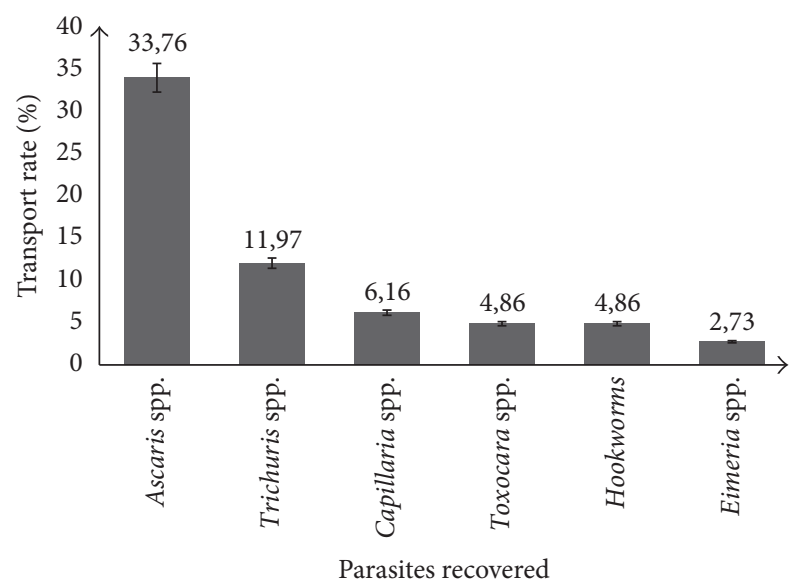

FIGURE 1: Transport rate of various parasites isolated from the cockroaches. Error bars $=95 \%$ CI.

Toxocara spp. and Hookworm have the same transport rate (4.86\%). Eimeria spp. oocysts $(2.73 \%)$ were less prevalent.

3.4. Predilection Sites of Infestation and Sex-Related Frequency. The prevalence of medically important parasites in relation to their repartition on cockroach is presented on Table 2. All the six parasites identified were more prevalent in the external surface (54.27\%) as compared to the internal surface (GIT; 38.51\%). Ascaris spp. eggs had the highest prevalence (49.64\%), followed by Trichuris spp. (16.46\%) Capillaria spp. (9.12\%), Toxocara spp. (7.82\%), Hookworms (4.98\%) ones, and Eimeria spp. oocysts (4.74\%).

The transport rate of medically important parasites identified in relation to cockroach sexes is illustrated in Table 2. Female cockroaches were more common carriers of parasites than the males. Ascaris spp. eggs were more carried (33.76\%), followed by those of Trichuris spp. (11.97\%), Capillaria spp. (6.16\%), Toxocara spp. (4.86\%), Hookworms (4.86\%), and oocysts of Eimeria spp. (2.73\%).

3.5. Parasite Recovery Rate from Cockroaches in Different Quarters and Capture Sites. The prevalence of identified parasite in relation to the quarter is shown in Table 3. Cockroaches in Lèlem carried more parasites (26.07\%) followed by those caught in Nkongsoung (20.97\%) and in Melong centre (17.29\%). Irrespective of quarters, Ascaris spp. eggs were more carried (33.77\%) followed by those of Trichuris spp. (11.97\%), Capillaria spp. (6.16\%), Toxocara spp. (4.86\%), Hookworm (4.86\%), and Eimeria spp. (2.73\%) oocysts.

The transport rate of medically important parasites identified in relation to the capture sites is shown in Table 3. This study revealed that cockroaches trapped from different sites (toilets, kitchens, and houses) shared the same parasites except for Toxocara spp. and Eimeria spp. which were absent on cockroaches caught in toilets. Cockroaches trapped in the toilets carried more medically important parasites $(32.37 \%)$ as compared to those from kitchens $(22.90 \%)$ and those from houses $(11.27 \%)$.

3.6. Prevalence of Parasitic Association. Four types of parasitic associations were recorded from the infested cockroaches. Single parasitic infestation was the most frequent $(32.58 \%)$ followed by double (11.37\%), triple (1.89\%), and quadruple $(0.24 \%)$ infestations. No cockroach had five parasites.

\section{Discussion}

Speculations have always been made on the involvement of cockroaches as possible vectors of diseases in communities [17]. But their role in the direct transmission of pathogens has seldom been established [16, 17]. Findings from this study indicated that cockroaches are reservoirs and mechanical transmitters of parasites. This is in agreement with previous studies done by Nagham et al. [15]; Bala and Sule [16] in Sokoto; Kassiri and Kazemi [21]; and Etim et al. [17], respectively, in Iraq, Iran, and Calabar, Nigeria.

Three species of cockroaches (Periplaneta americana, Blattella germanica, and Blatta orientalis) were found to be dominant in human habitations in the Melong Subdivision. This could be mainly due to their cosmopolitan distribution (association with human activity such as global commerce) and to their ability to reproduce and to survive more easily in tropical climate region. Although Chan et al. [22], AlMayali and Al-Yaqoobi [4], Ajero et al. [23], Ejimadu et al. [24], and Nigeria and Ameh [25], respectively, in Hawaii, Iraq, Owerri, Jos, and Zaria, Nigeria revealed that just two species of cockroaches (Periplaneta americana and Blattella germanica) were distributed in human habitations in their localities, out of the 3500 species of cockroaches discovered, 30 species have been adapted to human habitations [3]. 


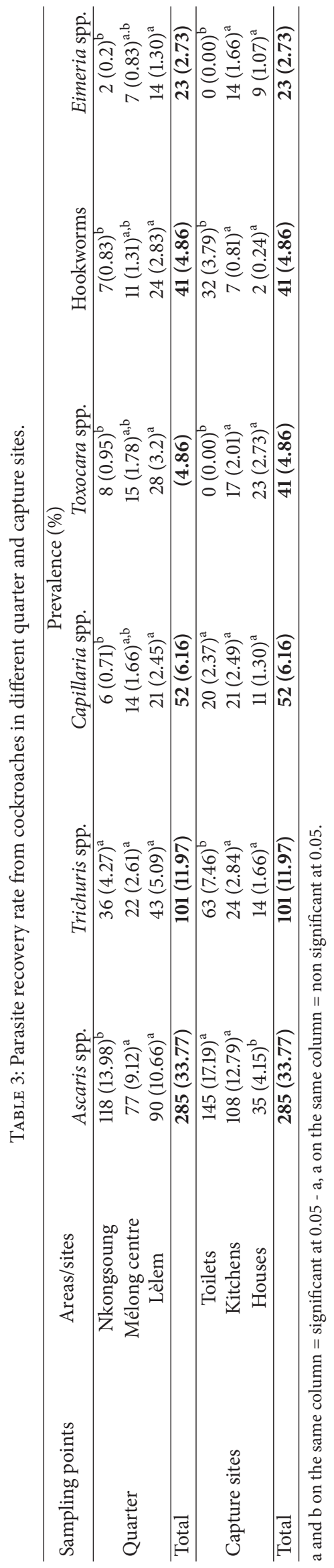


Periplaneta americana was the most frequently trapped in Melong Subdivision. This remark is in agreement with the findings of Ejimadu et al. [24] in Jos, Nigeria but is in variance with claims done by Ebeling [26] that B. germanica reproduces faster than any other residential cockroach growing from egg to reproductive adult. The ability of $P$. americana to be trapped more easily than $B$. germanica and $B$. orientalis could be due to their tendencies of being more active in search of food and sites to lay their eggs [16] while B. germanica and B. orientalis look to be sedentary in their behavior.

According to the capture sites, most cockroaches were caught in the toilets, followed by those caught in kitchens and in the houses. Because of the constant moisture, B. germanica and $B$. orientalis were not present in toilets while $P$. americana were present in all sites. This can be explained by its great adaptation in diverse habitats.

The importance of cockroaches as carriers of parasitic worms, eggs, cysts, or oocysts was based on some reports about the presence of parasitic forms on or in cockroaches [27]. The infective rate of $47.39 \%$ recorded in cockroaches trapped from three locations of Melong Subdivision might be an indication of their filthy feeding habit which makes them efficient carriers of these pathogens as earlier reported by Greenberg [27], Etim et al. [17], and Nagham et al. [15]. This infective rate reported (47.39\%) seemed to be higher than $18.41 \%$ observed by Ameh [25] in Zaria, Nigeria. However, it is lower than $67 \%, 77.52 \%, 98 \%$, and $100 \%$ reported by Chan et al. [22], Bala and Sule [16], El-Sherbini and Gneidy [28], and Kassiri and Kazemi [21], respectively, in Owerri, Nigeria, Arkilla and Sokoto, Nigeria, Egypt, and Iran. These variances could be attributed to the state of the parasite considered in its life cycle. In the present study, only embryonated eggs and sporulated oocysts were considered because at that stage, they present a great potential to infest humans and other animals. But as mentioned by Okafor and Elenwo [29], these infective rates recorded in cockroaches are associated with the poor rural condition of the community and to people's habit of defecating in the bush due to the lack of adequate toilet facilities and other essential amenities.

Ascaris spp. and Trichuris spp., respectively, responsible for ascariasis and trichuriasis in human, were the most encountered irrespective of predilection site of fixation, sex, capture sites, and quarters. The highest transport rate of Ascaris spp. eggs observed in the present study can be explained by the fact that Ascaris eggs have an inner shell layer of lipoprotein nature which makes them more resistant to harsh environmental conditions and air-borne [30] compared to the eggs of other nematodes. Another reason is that Ascaris eggs can survive in adverse environmental conditions. It might also be due to the overdispersion of Ascaris eggs in the environment as a single female Ascaris lays relatively large number of eggs (200,000 eggs/day) [31]. Relatively lower rates of transport of Trichuris eggs observed in this study might be due to their minimal dispersion as a single female Trichuris liberates relatively less numbers of eggs and also due to the easy destruction of embryonated eggs by desiccation.

Associated with their breeding system in the study area, the presence of pig and others domesticated animal farms around households may favor in one hand the distribution of Ascaris suum and Trichuris suis eggs which are morphologically nondistinguishable from Ascaris lumbricoides and Trichuris trichiura eggs and, on the other hand, eggs of others animal parasites. One interesting finding in this study was the detection of Capillaria spp. and Toxocara spp. eggs. Parasitic eggs come from animals which were not identified in similar studies. It might be due to the animal husbandry in the city.

Hence, the observation of Ascaris spp. and Trichuris spp. ova in the body surface of cockroaches is in agreement with the proposition that cockroaches are seriously involved in the epidemiology of soil transmitted helminthes (STH) as earlier reported by Etim et al. [17].

From this study, $P$. americana was more qualified $(p<$ $0.05)$ in the transport of parasites. This can be, as mentioned above, due to their adaptation in different environmental conditions and to their tendency of being more active in search of food and sites to lay their eggs [16]. Although the legs of many species of cockroaches are morphologically modified with comb like tubercles, spines or hairs, and useful during feeding and grooming processes, they are highly involved in the contamination of food and water in human dwellings [32, 33].

Based on capture sites, cockroaches caught from the toilets had more parasites because they were easily exposed to human faecal matter. As a result of their high mobility, they release these parasites (Ascaris spp., Trichuris spp., Capillaria spp., and Hookworm) carried on their bodies or within their alimentary canal on food or in drinking water when moving from toilet to kitchen and secondly from the kitchens to the houses; or on the contrary they enter in contact with other parasites like Toxocara spp. eggs and Eimeria spp. oocysts as observed in the present study.

Female cockroaches were significantly $(p<0.05)$ more vectorial than males. This may probably be due to their behavior which allows them to move more than the males in search of both food and sites to lay their eggs [16]. By this behavior, they come in contact with contaminated materials as they roam, making them more exposed to contact with pathogens.

Statistically, no significant difference was observed in the transport rate among the three-quarters. This simply allows the understanding that the parasites in these quarters have the same probability to be carried by cockroaches.

Mix infestations were observed among cockroach species and among different capture points. This result may probably explain the nonspecificity of cockroaches in their role of parasites vectors. Thus, the potential of cockroaches to transmit diseases should not be ignored or simply rejected but should be investigated further.

\section{Conclusion}

Cockroaches constitute an important reservoir for pathogens. Therefore, close contact with cockroaches especially in human dwellings should be discouraged. Due to the low standard of sanitation in Cameroon, especially in the MelongSubdivision, there is a need to properly educate the population on the dangers associated with cockroaches and how to control them. Environmental hygiene is very necessary 
and should be encouraged in every locality, to reduce the population and bad effects of arthropod pests especially cockroaches in human surroundings.

\section{Conflicts of Interest}

The authors declare that there are no conflicts of interest regarding the publication of this paper.

\section{Acknowledgments}

The authors wish to express their sincere thanks to the residents of the Melong Subdivision for their understanding and support to conduct this research.

\section{References}

[1] L. Zurek and C. Schal, "Evaluation of the German cockroach (Blattella germanica) as a vector for verotoxigenic Escherichia coli F18 in confined swine production," Veterinary Microbiology, vol. 101, no. 4, pp. 263-267, 2004.

[2] R. J. Kopanic, "Cockroaches as vectors of salmonella: laboratory and field trials," Journal of Food Protection, vol. 57, no. 2, pp. 125135, 1994.

[3] A. Kinfu and B. Erko, "Cockroaches as carriers of human intestinal parasites in two localities in Ethiopia," Transactions of the Royal Society of Tropical Medicine and Hygiene, vol. 102, no. 11, pp. 1143-1147, 2008.

[4] H. M. Al-Mayali and M. S. M. Al-Yaqoobi, "Parasites of cockroach Periplaneta Americana (L) in Al-Diwaniya Provinve," Irag Journal of Thi-Qar Science, vol. 2, no. 3, 2010.

[5] B. Tilahun, B. Worku, E. Tachbele, S. Terefe, H. Kloos, and W. Legesse, "High load of multi-drug resistant nosocomial neonatal pathogens carried by cockroaches in a neonatal intensive care unit at Tikur Anbessa specialized hospital, Addis Ababa, Ethiopia," Antimicrobial Resistance and Infection Control, vol. 1, article 12, 2012.

[6] B. Vazirianzadeh, M. Mehdinejad, and R. Dehghani, "Identification of bacteria which possible transmitted byPolyphaga aegyptica (Blattetea; Blattidea) in the region of Ahvaz," SW. Iran. J undishapur Journal of Microbiology, vol. 2, no. 1, pp. 36-40, 2009.

[7] P. Siachua, Kh. Pinmai, S. Somrithipol, and S. Tor-Udom, "Isolation of medically important fungi from cockroaches at Thammasat Chalermprakiat hospital," Thamasat, Medical Journal, vol. 8, no. 3, pp. 345-349, 2008.

[8] I. Uçkay, H. Sax, S. L.-D. Pietro et al., "Cockroaches (Ectobius vittiventris) in an intensive care unit, Switzerland," Emerging Infectious Diseases, vol. 15, no. 3, pp. 496-497, 2009.

[9] C. I. Iboh, L. B. Etim, J. T. Abraham, and R. O. Ajang, "Bacteria and parasites infestation of cockroaches in a developing community, South Eastern, Nigeria," International Journal of Bacteriology Research, vol. 2, no. 5, pp. 045-048, 2014.

[10] A. Mourier, Lutte intégrée contre deux insectes synanthropes: Blatella germanica et Cimex lectularius. Apports de l'écologie scientifique pour le conseil à l'officine. Pharmaceutical sciences. Dumas, 103p, 2014.

[11] R. Fotedar, E. Nayar, J. C. Samantray et al., "Cockroaches as vectors of pathogenic bacteria," Journal of Communicable Diseases, vol. 21, no. 4, pp. 318-322, 1989.
[12] T. K. Graczyk, R. Knight, and L. Tamang, "Mechanical transmission of human protozoan parasites by insects," Clinical Microbiology Reviews, vol. 18, no. 1, pp. 128-132, 2005.

[13] A. Salehzadeh, P. Tavacol, and H. Majhub, "Bacteria, fungi and parasitic contaminants of cockroaches in Public Hospitals of Hamedah," Iran Journal of Vectors Borne Diseases, vol. 44, pp. 105-110, 2007.

[14] Y. M. Tatfeng, M. U. Usuanlele, A. Orukpe et al., "Mechanical transmission of pathogenic organisms: the role of cockroaches," Journal of Vector Borne Diseases, vol. 42, no. 4, pp. 129-134, 2005.

[15] Y. A. Nagham, S. A. Anfal, and K. A. Israa, "Risks associated with cockroach Periplaneta americana as a transmitter of pathogen agents," Diyala Journal of Medicine, vol. 1, no. 1, pp. 91-97, 2011.

[16] A. Bala and H. Sule, "Vectorial potential of cockroaches in transmitting the parasites of medical importance in Arkilla, Sokoto Nigeria," Nigerian Journal of Basic and Applied Science, vol. 20, no. 2, pp. 111-115, 2012.

[17] S. E. Etim, O. E. Okon, P. A. Akpan, G. I. Ukpong, and E. E. Oku, "Prevalence of cockroaches (periplaneta americana) in households in calabar: public health implications. journal of public health and epidemiology," Journal of Public Health and Epidemiology, vol. 5, no. 3, pp. 149-152, 2013.

[18] H.-H. Pai, W.-C. Chen, and C.-F. Peng, "Cockroaches as potential vectors of nosocomial infections," Infection Control and Hospital Epidemiology, vol. 25, no. 11, pp. 979-984, 2004.

[19] L. Chopard, Orthoptéroïdes.Faune de France 56. Office central de faunistique. 358 p., 1951.

[20] Thienpont D., Roschette F., and Vanparijs O., Diagnostic Des Verminoses Par Examen Coprologique, vol. 29, Janssen Researche foundation, Beerse, Belgique, 1979.

[21] H. Kassiri and S. Kazemi, "Cockroaches [periplaneta americana (L.), dictyoptera; blattidae] as carriers of bacterial pathogens, khorramshahr County, Iran," Jundishapur Journal of Microbiology, vol. 5, no. 1, pp. 320-322, 2012.

[22] O. T. M. Chan, E. K. W. Lee, J. M. Hardman, and J. J. Navin, "The cockroach as a host for Trichinella and Enterobius vermicularis: implications for public health," Hawaii medical journal, vol. 63, no. 3, pp. 74-77, 2004.

[23] C. M. U. Ajero, C. N. Ukaga, and C. Ebirim, "The role of cockroaches (Blatta orientalis and Periplaneta americana) in mechanical transmission of parasites in households in Owerri, South East Nigeria," Nigerian Journal of Parasitology, vol. 32, no. 2, pp. 153-156, 2011.

[24] L. C. Ejimadu, O. N. Goselle, Y. M. Ahmadu, and N. N. James-Rugu, "Specialization of periplaneta americana (american cockroach) and blattella germanica (german cockroach) towards intestinal parasites: a public health concern," Journal of Pharmacy and Biological Sciences, vol. 6, pp. 23-32, 2015.

[25] Y. Ameh, Evaluation of the Role of Cockroaches as Carriers of Medically Important Parasites in Two Distinct Communities in Zaria, faculty of science Ahmadu Bello University, Nigeria, 2015.

[26] W. Ebeling, Urban Entomology, University of California Press, Davis, Calif, USA, 1978.

[27] I. Greenberg B, Ecology, Classification And Biotic Association, vol. 1, Princeton University Press, New Jersey, NJ, USA, 1973.

[28] G. T. El-Sherbini and M. R. Gneidy, "he role of cockroaches and flies in mechanical transmission of medical important parasites," Journal of Entomology and Nematology, vol. 3, no. 7, pp. 98-104, 2011. 
[29] E. Okafor and A. C. Elenwo, "Human infecting parasitic worms, in cockroaches from Odau in the Niger delta region of Nigeria," International Journal of Natural Sciences Research, vol. 2, no. 10, pp. 176-184.

[30] J. D. Smyth, Animal Parasitology, Cambridge university press, Cambridge, UK, 1996.

[31] E. J. L. Soulsby, The Journal of Parasitology, Baillere Tindal, London, UK, 7th edition, 1982.

[32] B. S. Draser and P. A. Barrow, Intestinal Microbiology, American Society of Microbiology, Washington, Wash, USA, 1985.

[33] J. R. Busvine, Arthropod vectors of diseases. Disease spread by insects other than Diptera, Edward Arnold Publisher, London, UK, 2nd edition, 1983. 

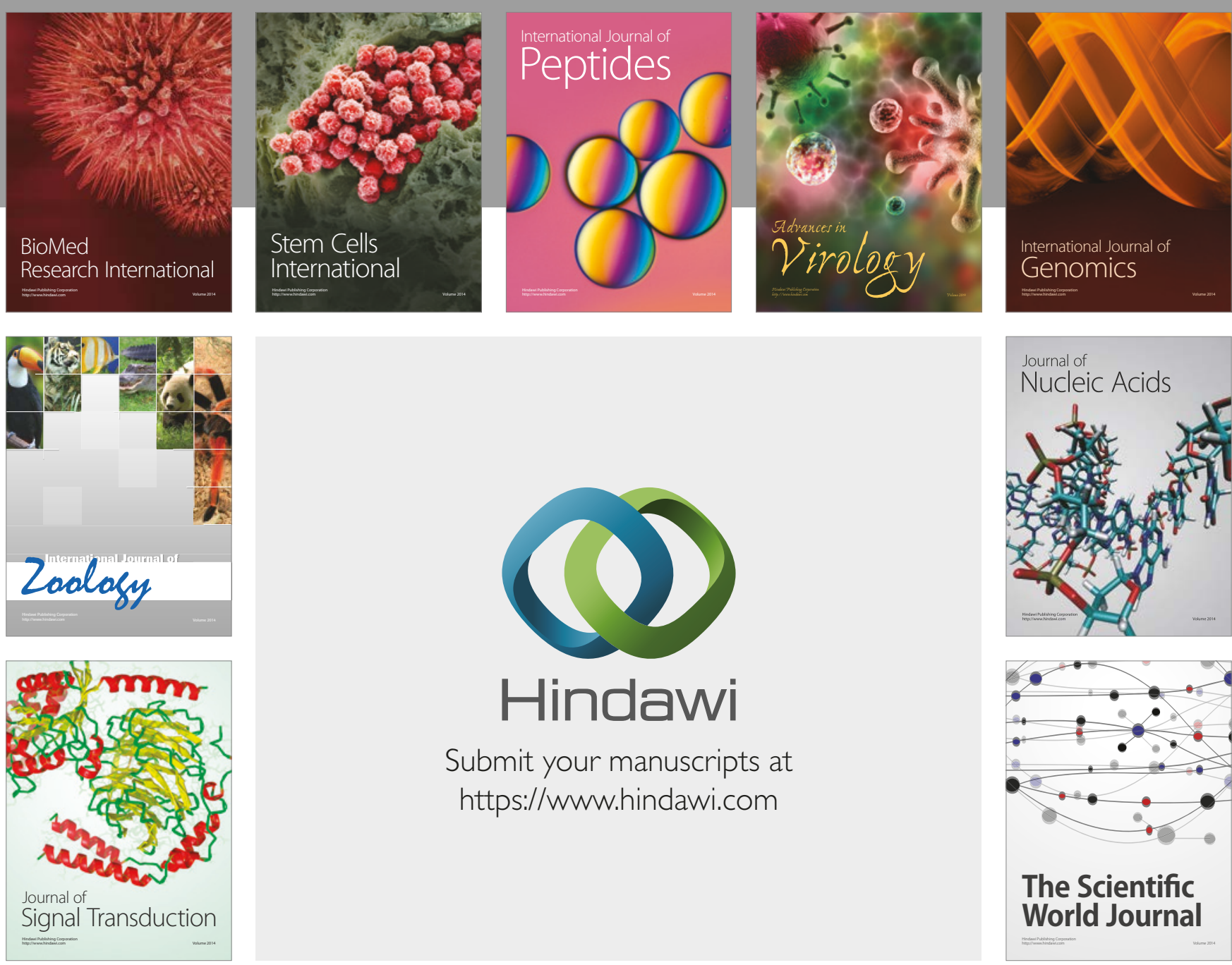

Submit your manuscripts at

https://www.hindawi.com
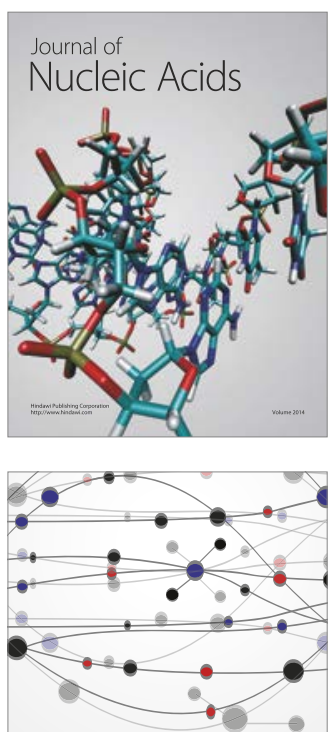

The Scientific World Journal

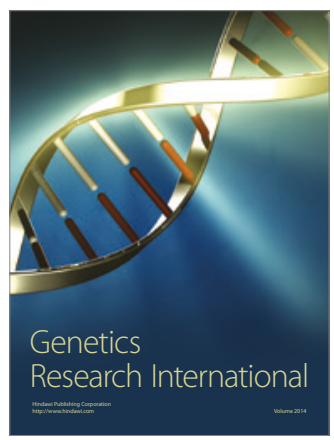

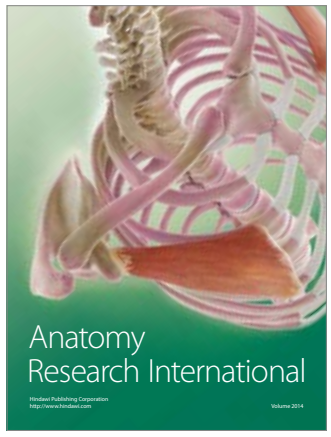

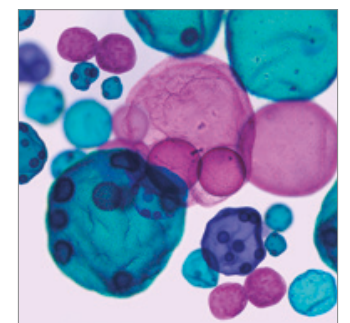

International Journal of Microbiology
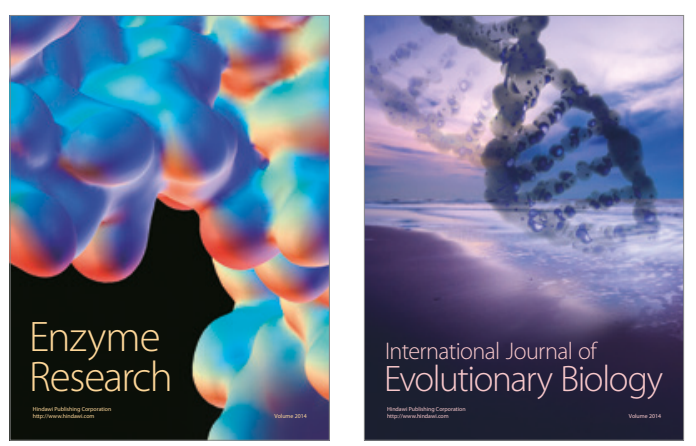
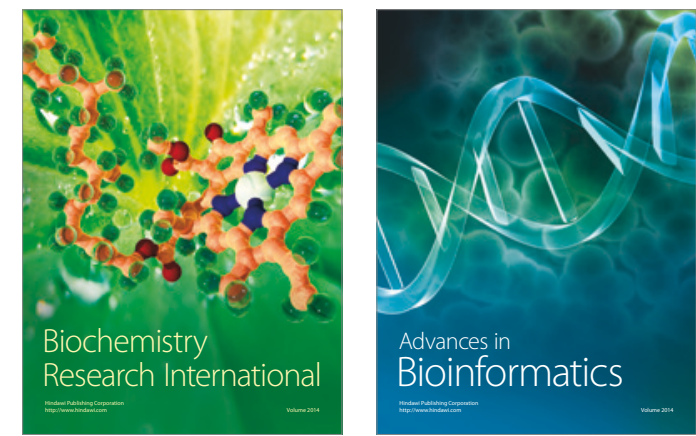

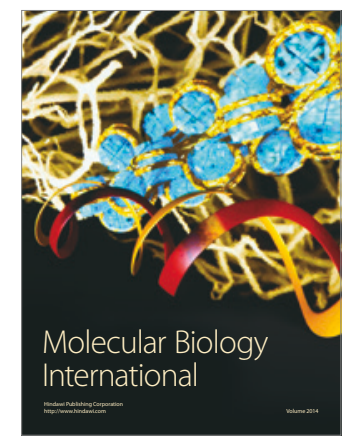

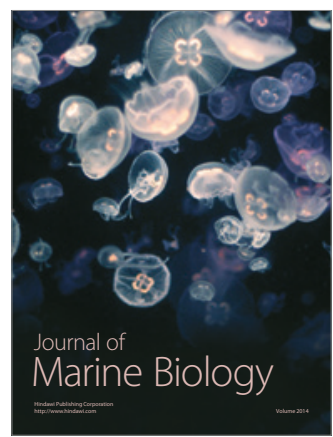

